\title{
8
}
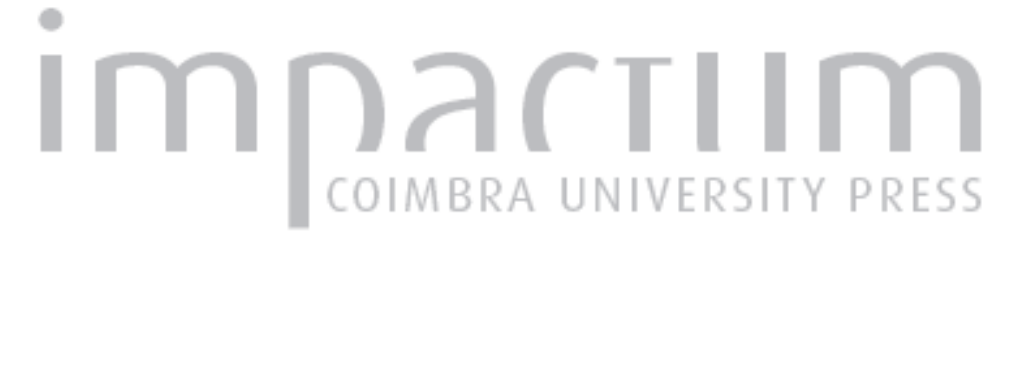

Quem tem medo dos jornalistas? (media, segredo de justiça e perícias médicolegais)

\author{
Autor(es): $\quad$ Raposo, Vera Lúcia
}

Publicado por: Imprensa da Universidade de Coimbra

URL persistente:

URI:http://hdl.handle.net/10316.2/33146

DOI:

DOI:http://dx.doi.org/10.14195/1647-8630_19_5

Accessed : $\quad$ 26-Apr-2023 14:14:00

A navegação consulta e descarregamento dos títulos inseridos nas Bibliotecas Digitais UC Digitalis, UC Pombalina e UC Impactum, pressupõem a aceitação plena e sem reservas dos Termos e Condições de Uso destas Bibliotecas Digitais, disponíveis em https://digitalis.uc.pt/pt-pt/termos.

Conforme exposto nos referidos Termos e Condições de Uso, o descarregamento de títulos de acesso restrito requer uma licença válida de autorização devendo o utilizador aceder ao(s) documento(s) a partir de um endereço de IP da instituição detentora da supramencionada licença.

Ao utilizador é apenas permitido o descarregamento para uso pessoal, pelo que o emprego do(s) título(s) descarregado(s) para outro fim, designadamente comercial, carece de autorização do respetivo autor ou editor da obra.

Na medida em que todas as obras da UC Digitalis se encontram protegidas pelo Código do Direito de Autor e Direitos Conexos e demais legislação aplicável, toda a cópia, parcial ou total, deste documento, nos casos em que é legalmente admitida, deverá conter ou fazer-se acompanhar por este aviso.

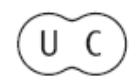




\section{Quem tem medo dos jornalistas? (media, segredo de justiça e perícias médico-legais)}

Vera Lúcia Raposo ${ }^{1}$

\section{As dimensões do problema}

Não raramente surgem nos media noticias que divulgam dados constantes de relatórios apresentados pelos serviços de medicina legal no âmbito de um processo judicial. Desde noticias que divulgam a taxa de alcoolemia de um político que conduzia embriagado, até outras que referem o uso de substâncias dopantes por parte de um atleta numa competição olímpica, hoje em dia, e cada vez mais, cada momento da nossa vida aparece exposto nas páginas dos jornais ou nos ecrãs de televisão.

Para além dos problemas de privacidade que estas notícias inelutavelmente suscitam, o problema agudiza-se quando a divulgação de informações por meio da comunicação social tem por objecto acontecimentos que ainda estão a ser judicialmente investigados. O que significa que não se trata de uma qualquer informação, mas sim de informações a coberto de uma esfera de segredo.

Entre as informações cuja divulgação suscita mais acérrima oposição encontram-se as constantes dos relatórios médico-legais. As perícias médicolegais ocorrem sempre que sejam necessários conhecimentos técnico-científicos de carácter médico-legal, com vista à percepção e apreciação de certos factos. Incumbem aos Institutos de Medicina Legal, os quais devem concretizar os resultados a que os exames chegaram num relatório médico-legal. Estes relatórios são, por conseguinte, um meio de prova que se apresenta, juntamente com outros tantos, num determinado processo judicial.

1 Assistente da Faculdade de Direito da Universidade de Coimbra; Advogada 


\section{Aplicação das regras de processo criminal ou das regras de acesso aos documentos administrativos?}

Teoricamente, o acesso a documentos emanados pelo Instituto de Medicina Legal (relatórios de autópsias, resultados de exames) poderia ser regulamentado por um de dois dispositivos legais distintos: ou se entende que se trata de documentos administrativos e se lhes aplica a Lei de Acesso aos Documentos Administrativos (a Lei n. ${ }^{\circ}$ 46/2007, de 24 de Agosto) e o Código de Procedimento Administrativo; ou, em alternativa, estes documentos são concebidos como parte intrínseca de um processo judicial, cujo acesso se deverá orientar pelas normas que dominam o processo em causa. Estes processos poderão ser de diversa índole: civil, laboral ou criminal. As questões mais controversas relacionam-se com o processo criminal, especialmente quando este se encontre ainda em segredo de justiça. Efectivamente, embora também no contexto do processo civil se realizem perícias médico-legais, é no contexto do processo criminal que a questão mais se problematiza e, por conseguinte, será sobre esta temática que nos debruçaremos.

A posição que nos parece mais correcta - e que, além do mais, tem sido reiteradamente confirmada pela jurisprudência e pelos pareceres da Procuradoria-Geral da República (PGR) - é aquela que advoga que as normas a seguir neste particular são as consagradas no Código de Processo Penal (CPP).

A justificação desta solução reside na própria natureza dos relatórios médico-legais, que vivem na dependência do processo criminal ao qual dizem respeito. Por conseguinte, o acesso de terceiros a esses dados deverá estar submetido aos poderes das entidades jurisdicionais que a cada momento comandam o processo criminal, ou seja, aos juízes e magistrados do Ministério Público. É a estes que incumbe a direcção e responsabilidade pelo conteúdo dos processos judiciais. É também a eles que cabe avaliar o acesso aos referidos documentos com base nas circunstâncias do caso e nas normas processuais criminais atinentes em cada momento, especialmente as relativas à consulta e obtenção de cópias ou certificados.

É certo que uma vez que as cópias de estes relatórios se encontram em poder do Estado poderíamos pensar que lhes era aplicável o regime de acesso aos documentos administrativos, a lei n. ${ }^{\circ}$ 46/2007, de 24 de Agosto, que transpôs para a ordem jurídica nacional a Directiva n. ${ }^{\circ}$ 2003/98/CE, do Parlamento e do Conselho, de 17 de Novembro, relativa à utilização de informações no sector público. Segundo o art. 3.\%/1/a desta lei, são considerados "documentos administrativos" todos os suportes de informação - em forma escrita, visual, sonora, electrónica ou outra - que se encontrem em poder das 
entidades referidas no art. $4 .^{\circ}$ da mesma lei ${ }^{2}$. Mas o art. 3.\%/2/b da mesma lei exclui do âmbito da referida definição os documentos que não relevem da actividade administrativa ${ }^{3}$.

Conquanto os relatórios médico-legais sejam documentos elaborados pelos serviços de medicina legal, parte integrante da administração do Estado, em bom rigor são os tribunais que determinam a sua elaboração e é em relação à função judicial que estão predestinados. Por este motivo não são propriamente documentos administrativos. Uma vez que a referida lei se restringe organicamente à Administração Pública não se pode considerar que englobe concomitantemente os tribunais.

Em Portugal os serviços de medicina legal encontram o seu regime no Decreto-Lei n. ${ }^{\circ}$ 131/2007, de 27 de Abril, que aprova a orgânica do Instituto Nacional de Medicina Legal. Um dos seus princípios basilares é aquele segundo o qual os serviços médico-legais têm por função coadjuvar os tribunais na aplicação da justiça (art. 3.\%/2/b), daqui derivando que em termos organizacionais estão incluídos no Ministério da Justiça (art. 1.\%/2) ${ }^{4}$. Destes preceitos se deduz a dependência da actividade do Instituto Nacional de Medicina Legal face ao concreto processo judicial no seio do qual tenha sido solicitada a sua intervenção.

2 Art. 3.\%1/a da Lei n. ${ }^{\circ}$ 46/2007 - Para efeitos da presente lei, considera-se: a) «Documento administrativo» qualquer suporte de informação sob forma escrita, visual, sonora, electrónica ou outra forma material, na posse dos órgãos e entidades referidos no artigo seguinte, ou detidos em seu nome.

Art. 4. $\%$ da Lei n. ${ }^{\circ}$ 46/2007 - A presente lei aplica-se aos seguintes órgãos e entidades:

a) Órgãos do Estado e das Regiões Autónomas, que integrem a Administração Pública;

b) Demais órgãos do Estado e das Regiões Autónomas, na medida em que desenvolvam funções materialmente administrativas;

c) Órgãos dos institutos públicos e das associações e fundações públicas;

d) Órgãos das empresas públicas;

e) Órgãos das autarquias locais e das suas associações e federações;

f) Órgãos das empresas regionais, intermunicipais e municipais;

g) Outras entidades no exercício de funções administrativas ou de poderes públicos.

3 Art. 3.\%/2/b da Lei n. ${ }^{\circ}$ 46/2007 - Não se consideram documentos administrativos, para efeitos da presente lei:

b) Os documentos cuja elaboração não releve da actividade administrativa, designadamente referentes à reunião do Conselho de Ministros e de secretários de Estado, bem como à sua preparação.

4 Art. 3.\%/2/b do Decreto-Lei n. ${ }^{\circ}$ 131/2007 - São atribuições do INML, I. P.: Cooperar com os tribunais e demais serviços e entidades que intervêm no sistema de administração da justiça, realizando os exames e as perícias de medicina legal e forenses que lhe forem solicitados, nos termos da lei, bem como prestar-lhes apoio técnico e laboratorial especializado, no âmbito das suas atribuições;

Art. 1.\%/2 do Decreto-Lei n. ${ }^{\circ}$ 131/2007 - O INML, I. P., prossegue atribuições do Ministério da Justiça (MJ), sob superintendência e tutela do respectivo ministro. 
Também o regime das perícias médico-legais - a Lei n. ${ }^{\circ} 45 / 2004$, de 19 de Agosto - confirma a dependência dos serviços de medicina legal em relação a um determinado processo judicial e às correspondentes autoridades judiciárias. De acordo com o seu art. 3.\%1, quando as perícias médico-legais sejam solicitadas no decurso de um processo judicial têm as mesmas que ser precedidas de um despacho emanado por autoridade judiciária ou policial ${ }^{5}$. O carácter coadjuvante do Instituto de Medicina Legal em relação a uma investigação criminal é corroborado pelo art. $4 .^{\circ}$ do referido diploma, que legitima esta entidade para receber denúncias de crimes, embora cominandolhe o dever de reenvio ao Ministério Público no mais breve prazo possível. Simultaneamente, autoriza o Instituto a praticar os actos cautelares que se revelem necessários e urgentes para a conservação dos meios de prova ${ }^{6}$.

As referidas normas comprovam a necessária conexão entre a perícia médico-legal e um específico processo, que tem natureza judicial e não administrativa. Consequentemente, as regras aplicáveis deverão aquelas que regulam o conhecimento do processo por parte de terceiros - normas processuais penais, portanto - e não as que facultam o acesso a documentos administrativos $^{7}$.

\section{Segredo de justiça}

A tramitação do processo criminal português divide-se, basicamente, em três fases, sendo que a cada uma delas corresponde uma entidade de controlo: i) o inquérito, período de investigação por excelência, sob a direcção do

5 Art. 3.\%1 da Lei n. ${ }^{\circ}$ 45/2004 - As perícias médico-legais solicitadas por autoridade judiciária ou judicial são ordenadas por despacho da mesma, nos termos da lei de processo, não sendo, todavia, aplicáveis às efectuadas nas delegações do Instituto ou nos gabinetes médico-legais as disposições contidas nos artigos $154 .^{\circ}$ e $155^{\circ}$ do Código de Processo Penal.

6 Art. $4 .^{\circ}$ da Lei n. ${ }^{\circ}$ 45/2004

1. As delegações e os gabinetes médico-legais do Instituto podem receber denúncias de crimes, no âmbito da actividade pericial que desenvolvam, devendo remetê-las no mais curto prazo ao Ministério Público.

2. Sempre que tal se mostre necessário para a boa execução das perícias médico-legais, as delegações e os gabinetes médico-legais do Instituto podem praticar os actos cautelares necessários e urgentes para assegurar os meios de prova, procedendo, nomeadamente, ao exame, colheita e preservação dos vestígios, sem prejuízo das competências legais da autoridade policial à qual competir a investigação.

7 Confirmando esta ideia, o parecer da PGR n. ${ }^{\circ}$ P000302005, de 2 de Junho de 2005, no seguimento de um outro parecer dessa mesma entidade, o parecer n. ${ }^{\circ} \mathrm{P} 000291998$, de 24 de Abril de 1998. 
Ministério Público; ii) a instrução, em boa verdade uma fase facultativa, que cabe ao juiz de instrução; iii) e o julgamento, dirigido pelo juiz de julgamento.

Ao contrário do modelo de processo criminal que nos chega da experiência norte-americana, entre nós, tradicionalmente, uma parte substancial do processo está subtraída ao escrutínio público, muito embora a recente reforma processual penal tenha alargado o alcance da publicidade.

Anteriormente o art. 86. ${ }^{\circ}$ do CPP afirmava que o processo criminal era público a partir da fase da instrução ou a partir do momento em que esta não pudesse mais ser requerida (embora estivesse prevista a possibilidade de o Ministério Público poder determinar a publicidade externa do processo, desde que tal decisão não prejudicasse nem a investigação nem os direitos dos participantes processuais ou das vítimas e, concomitantemente, contasse com a concordância do arguido ou arguidos), ao passo que a instrução seria em principio pública, excepto se requerida pelo arguido e este se opusesse à publicidade da mesma.

Diferentemente, hoje a norma estipula simplesmente que o processo é público, excepto se os participantes processuais manifestarem vontade contrária. Significa isto que a publicidade impera hoje desde o primeiro momento $^{8}$. Efectivamente, atendendo ao interesse da investigação e/ou ao da protecção dos sujeitos e participantes processuais, o n. ${ }^{\circ} 2$ do art. $86 .^{\circ}$ permite que o juiz de instrução declare o inquérito secreto, depois de ouvido o Ministério Público sobre a questão e mediante requerimento dos interessados. Concomitantemente, no seu n. 3 autoriza o próprio Ministério Público a apresentar esse pedido ao juiz de instrução, eventualmente no seguimento de um requerimento dos mesmos interessados ${ }^{9}$. E, de facto, é na fase de inquérito que a ruptura do segredo se revela mais problemática (note-se que a actual redacção das referidas normas não faz menção ao segredo durante a instrução, pelo que se presume ser esta sempre pública), precisamente porque

8 Art. 86.\%1 do CPP - O processo penal é, sob pena de nulidade, público, ressalvadas as excepções previstas na lei.

Esta norma leva a que se afirme que "hoje, apesar do art. 20. ${ }^{\circ}$ n. ${ }^{\circ} 3$, não há segredo de justiça, há apenas excepções à publicidade" (MAGISTRADOS DO MINISTÉRIO PÚBLICO DO DISTRITO JUDICIAL DO PORTO, Código de Processo Penal (Comentários e Notas Práticas), Coimbra Editora, Coimbra, 2009, p. 223).

9 Art. $86 . \% 2$ do $\mathrm{CPP}$ - O juiz de instrução pode, mediante requerimento do arguido, do assistente ou do ofendido e ouvido o Ministério Público, determinar, por despacho irrecorrível, a sujeição do processo, durante a fase de inquérito, a segredo de justiça, quando entenda que a publicidade prejudica os direitos daqueles sujeitos ou participantes processuais.

Art. 86.\%3 do CPP - Sempre que o Ministério Público entender que os interesses da investigação ou os direitos dos sujeitos processuais o justifiquem, pode determinar a aplicação ao processo, durante a fase de inquérito, do segredo de justiça, ficando essa decisão sujeita a validação pelo juiz de instrução no prazo máximo de setenta e duas horas. 
nos reportamos a uma fase em que, por um lado, ainda não existe qualquer acusação, de modo que a presunção de inocência do arguido manifesta-se com grande vigor, pelo que devemos ser particularmente prudentes em qualquer eventual ataque a essa presunção; por outro lado, sendo esta uma fase de investigação por excelência, é precisamente aqui que a imaculabilidade das diligências investigatórias se torna vital, obstante à divulgação de informações susceptíveis de a enfraquecer.

Como se referiu, a decisão de afastamento da publicidade durante o inquérito cabe, em princípio, ao Ministério Público, embora este careça sempre do assentimento do juiz de instrução (art. 86. $\left.{ }^{\circ} / 3 \mathrm{CPP}\right)^{10}$. Mesmo depois do processo ter sido remetido para o nível de segredo pode o Ministério Público decretar a qualquer momento o seu levantamento, oficiosamente ou a requerimento do arguido, do assistente ou do ofendido (art. 86. $\%$ CPP) ${ }^{11}$. Também o juiz de instrução tem legitimidade para levantar o segredo no seguimento de um requerimento de um dos referidos sujeitos, que tenha sido desatendido pelo Ministério Público; decide por despacho irrecorrível e mesmo contra a oposição do Ministério Público (art. 86.\%/5 CPP) ${ }^{12}$. O motivo pelo qual não cabe apenas às autoridades judiciárias a avaliação da necessidade do regime de segredo, mas também ao arguido, ao assistente ou ao ofendido, reside na dualidade de interesses em causa: por um lado, o interesse público na realização da justiça; por outro, o interesse individual na privacidade e no bom-nome dos envolvidos ${ }^{13}$.

10 Esta obrigação de homologação da decisão do Ministério Público por parte do juiz de instrução não foi considerada inconstitucional no acórdão do Tribunal Constitucional n. 110/2009, de 11 de Março de 2009. Porém, salientou-se nos votos de vencido (da juíza Conselheira Maria João Antunes) que "[a] validação, pelo juiz de instrução, da determinação do Ministério Público em aplicar ao processo, durante a fase de inquérito, o segredo de justiça, quando os interesses da investigação o justifiquem, põe em causa a repartição constitucional das funções de investigação e acusação, por um lado, e julgamento, por outro". Ou seja, o novo regime coloca em causa a própria estrutura processual desde há muito seguida entre nós: o processo acusatório integrado por um princípio de investigação (Manuel da Costa ANDRADE, Bruscamente no Verão Passado - A Reforma do Código de Processo Penal, Coimbra Editora, 2009, p. 62).

Pronunciou-se no mesmo sentido o recente parecer da PGR n. ${ }^{\circ}$ P000252009, publicado a 17 de Novembro de 2009.

11 Art. 86.\% do CPP - No caso de o processo ter sido sujeito, nos termos do número anterior, a segredo de justiça, o Ministério Público, oficiosamente ou mediante requerimento do arguido, do assistente ou do ofendido, pode determinar o seu levantamento em qualquer momento do inquérito.

12 Art. 86. $\%$ do CPP - No caso de o arguido, o assistente ou o ofendido requererem o levantamento do segredo de justiça, mas o Ministério Público não o determinar, os autos são remetidos ao juiz de instrução para decisão, por despacho irrecorrível.

13 Acórdão do Tribunal da Relação do Porto de 7 de Maio de 2008, proferido no processo n. ${ }^{\circ}$ 0811925 . 
Por outras palavras, hodiernamente, a fase inicial do processo criminal só é secreta se essa for a solução considerada preferível depois de uma ponderação judicial das circunstâncias do caso concreto, regime este que remete o segredo de justiça para um plano de excepcionalidade.

Mesmo quando tenha sido decretado o segredo de justiça a lei prevê circunstâncias que nas quais se permite a sua quebra. Desde logo, quando tal seja necessário à reposição da verdade, ao exercício de direitos por parte de certas pessoas, ou à prestação de esclarecimentos públicos destinados ao estabelecimento da verdade e que não prejudiquem a investigação, ou ainda esclarecimentos públicos que visem garantir a segurança de pessoas e bens ou a tranquilidade pública. Finalmente, quando se destine à emissão de certidão de acto ou documento para fins processuais.

A ideia do "segredo de justiça" não é uma mera excentricidade do legislador criminal, que possa ser alterada ao sabor dos acontecimentos e das mundividências vigentes em cada momento. Na verdade, o conceito goza inclusive de protecção constitucional, pois o art. 20.\%/3 da Constituição da República Portuguesa (CRP) estipula que a lei define e assegura a adequada protecção do segredo de justiça. A sua manutenção é tão relevante que a violação do segredo consubstancia inclusive um delito criminal (art. 371. ${ }^{\circ}$ do Código Penal, CP $)^{14}$.

Qual o fundamento de uma tão extensa protecção do carácter secreto do processo penal na tradição legal portuguesa? Na protecção dos interesses envolvidos. Antes de mais, o interesse do Estado na realização da justiça, reclamando a exclusão dos trâmites processuais de pessoas estranhas ao processo. Esta preocupação assume particular relevo em relação à Comunicação Social. Indubitavelmente, o envolvimento da impressa pode acarretar consigo especulações sensacionalistas e assim "perturbar a imperturbabilidade"

Maria João ANTUNES ("O Segredo de Justiça e os Direitos de Defesa do Arguido Sujeito a Medida de Coacção", in Liber Discipulorum para Jorge de Figueiredo Dias, Coimbra, 2003, p. 1137) refere a "tarefa de concordância prática das finalidades, irremediavelmente conflituantes, apontadas ao processo penal: a realização da justiça e a descoberta da verdade material, a protecção perante o Estado dos direitos fundamentais das pessoas e o restabelecimento, tão rápido quanto possível, da paz jurídica posta em causa pelo crime e a consequente reafirmação da validade da norma violada". Mais à frente, continua a autora (ainda que referindo-se à versão do CPP de 1998, que ainda menor abertura apresentava à publicidade): "Como o reconhecimento daquelas três finalidades supõe a aceitação da impossibilidade da sua total harmonização, a concordância prática das finalidades conflituantes impôs limitações e até derrogações ao princípio da publicidade" (p. 1242).

14 Art. $371 .^{\circ}$ do CP - Quem, independentemente de ter tomado contacto com o processo, ilegitimamente der conhecimento, no todo ou em parte, do teor de acto de processo penal que se encontre coberto por segredo de justiça, ou a cujo decurso não for permitida a assistência do público em geral, é punido com... 
das investigações, conduzindo a autênticas condenações na arena pública. De forma mais especifica, diremos que aquilo que se pretende é subtrair as diligências processuais ao conhecimento dos suspeitos que, por via do domínio das ocorrências, poderiam actuar de modo a transtornar o processo, destruir e adulterar provas, e inclusive subtrair-se à actuação da justiça. Por outro lado, estes mesmos suspeitos são igualmente portadores de direitos e interesses dignos de tutela, nomeadamente o interesse em manter o processo secreto, como forma de salvaguardar o seu bom-nome e a sua reputação e a não esvaziar a respectiva presunção de inocência. Até as supostas vítimas poderão estar interessadas em preservar os factos ocorridos, sobretudo em certos tipos de criminalidade, e em particular nos crimes sexuais.

Atendendo à protecção dos referidos valores, direitos e interesses, há quem qualifique de inconstitucional a actual abertura do processo à publicidade interna e, por maioria de razão, à externa ${ }^{15}$.

\subsection{Comunicação social e segredo de justiça}

Dizer que um processo é público implica, entre outras consequências, que a Comunicação Social goza da faculdade de narrar actos do processo ou de reproduzir os seus termos, o mesmo valendo para aqueles actos aos quais é permitia a assistência do público(art. $86 . \% / 6$ do $\mathrm{CPP})^{16}$. Significa isto, $a$ contrario, que em presença do segredo de justiça os meios de comunicação social não desfrutam de tal possibilidade, nem tão pouco quando, mesmo tendo já sido levantado o segredo de justiça, se trata de acto em relação ao qual foi proibida a assistência do público.

15 Paulo Pinto de AlbuQuerque, Comentário do Código de Processo Penal (à Luz da Constituição da República e da Convenção Europeia dos Direitos do Homem), Universidade Católica Editora, Lisboa, 2007, p. 243 ss.: "O legislador quer agora um outro regime de segredo de justiça, mas ele viola frontalmente os limites "essenciais" ou "constitutivos" do conceito de segredo de justiça previsto no art. 20, n. ${ }^{\circ} 3$ da CRP”. Em conformidade, conclui o autor pela inconstitucionalidade das normas dos n..$^{\circ}$ s $2,3,4,5$ e 6 do art. $86 .^{\circ}$, por violação dos arts. 2. ${ }^{\circ}, 20 \% / 1 / 3,32 . \% / 5 / 7$ e $219 . \%$ CRP.

M. Maia GONÇALVES (Código de Processo Penal Anotado, Legislação Complementar (17. ${ }^{\circ}$ ed.), Almedina, Coimbra, 2009, p. 254): “O regime implantado pela Lei n. ${ }^{\circ}$ 48/2007, mormente através dos dispositivos dos $n^{\circ} \mathrm{s} 1,2$ e 3 deste art. $86 .^{\circ}$, contrariamente ao pensamento legislativo-constitucional, não dá adequada protecção ao segredo de justiça, designadamente nos momentos da fase inicial do inquérito, em que mais frequentemente se impõe".

16 Art. 86.\% do CPP - A publicidade do processo implica, nos termos definidos pela lei e, em especial, pelos artigos seguintes, os direitos de:

b) Narração dos actos processuais, ou reprodução dos seus termos, pelos meios de comunicação social; 
Em suma, o segredo de justiça vincula todas as entidades que tenham, de alguma forma, contacto com o processo (art. 86. $/ 8$ do CPP) ${ }^{17}$. A aplicação desta regra aos jornalistas não tem sido considerada como violadora das liberdades de imprensa e de expressão ${ }^{18}$.

A consulta dos autos e a obtenção de certificados por parte de pessoas estranhas ao processo vem regulamentada no art. $900^{\circ}$ do CPP, que nos diz que esta possibilidade cabe àquele que invocar um interesse legítimo, desde que o documento visado não seja parte de um processo em segredo de justiça ${ }^{19}$. Cabe à autoridade competente em cada fase processual determinar, primeiro, se o processo se encontra em segredo de justiça, depois, se a requerente é titular de um interesse legítimo.

Todavia, quando o acesso seja reivindicado por jornalistas entra em jogo uma outra norma, especificamente direccionada para os órgãos de comunicação social, o art. 88..$^{\circ}$ do CPP. Este preceito contem um regime de favor, mais benéfico para os jornalistas do que o estipulado para o público em geral, na medida em que lhes permite a consulta dos autos e a obtenção de cópia, extracto ou certidão nos processo em que vigore a publicidade externa, bastando para isso alegarem um interesse legítimo.

Ainda assim, não me parece que exima os jornalistas da proibição de acesso aos dados relativos à vida privada que não constituam meio de prova, tal como vem referido no art. $86 . \%$ de $\mathrm{CPP}^{20}$. Se essa tivesse sido a intenção do

17 Art. 86.\% do CPP - O segredo de justiça vincula todos os sujeitos e participantes processuais, bem como as pessoas que, por qualquer título, tiverem tomado contacto com o processo ou conhecimento de elementos a ele pertencentes, e implica as proibições de:

a) Assistência à prática ou tomada de conhecimento do conteúdo de acto processual a que não tenham o direito ou o dever de assistir;

b) Divulgação da ocorrência de acto processual ou dos seus termos, independentemente do motivo que presidir a tal divulgação.

18 Pronunciando-se a favor da solução legal, por a considerar respeitadora da liberdade de expressão e de imprensa e eficaz em termos de harmonização de interesses conflituantes, MAGISTRADOS DO MINISTÉRIO PÚBLICO DO DISTRITO JUDICIAL DO PORTO, Código de Processo Penal..., p. 235: "Apresentam-se, por isso, tais restrições perfeitamente adequadas aos fins visados, que são legítimos e públicos, sem exceder o estritamente necessário a tais fins e sem comprometer o essencial do direito de informar. Ou seja, trata-se de restrições proporcionais, justificadas e necessárias, não violando os preceitos constitucionais".

19 Art. 90.\%1 do CPP - Qualquer pessoa que nisso revelar interesse legítimo pode pedir que seja admitida a consultar auto de um processo que se não encontre em segredo de justiça e que lhe seja fornecida, à sua custa, cópia, extracto ou certidão de auto ou de parte dele. Sobre o pedido decide, por despacho, a autoridade judiciária que presidir à fase em que se encontra o processo ou que nele tiver proferido a última decisão.

20 Art. 86.\%7 do CPP- A publicidade não abrange os dados relativos à reserva da vida privada que não constituam meios de prova. A autoridade judiciária especifica, por despacho, oficiosamente ou a requerimento, os elementos relativamente aos quais se mantém o segredo 
legislador teria consagrado expressamente uma tal excepção no texto do art. 88. ${ }^{\circ}$ do CPP, o que não sucedeu. $\mathrm{O}$ art. 88. $\% 1$ do CPP limita-se a estabelecer que os meios de comunicação podem, dentro dos limites legais, relatar os actos processuais que sejam públicos, ou seja, que não se encontrem a coberto do segredo de justiça ou aos quais se permita a assistência do público em geral ${ }^{21}$ (todavia, não autoriza a reprodução de peças ou documentos até que seja proferida a decisão de 1. ${ }^{a}$ instância, com excepção dos casos em que exista uma autorização da autoridade judiciária que preside à fase processual em causa, ou ainda quando os referidos documentos hajam sido obtidos mediante um certificado que refira a finalidade especifica à qual se dirigem, segundo o disposto no seu n. $\left.{ }^{\circ} 2\right)^{22}$. Nada dizendo em relação às referidas informações que contendem com a vida privada dos sujeitos processuais e que não sejam meio de prova, concluímos que vale neste ensejo a proibição geral do art. 86. \% 7 do CPP. Mas, mais do que isso, é nosso entender que semelhante proibição de divulgação (excepto contanto com o consentimento da pessoa a quem digam respeito) se estende a qualquer informação da vida íntima da pessoa (sendo a intimidade o núcleo mais restrito e protegido da privacidade), ainda que materializada num meio de prova. Embora o CPP, em si mesmo, não faça tal especificação, tal proibição resulta do regime geral das leis de protecção de dados pessoais, e até do texto constitucional.

No que respeita em particular aos relatórios médicos-legais deve ter-se em consideração o n. ${ }^{\circ} 2$ do art. $90 .^{\circ}$ do CPP, que estabelece que autorização que venha a ser prestada para permitir o acesso a documentos não significa que a reprodução dos mesmos possa ser levada a cabo na comunicação social $^{23}$. Atendendo ao facto de os relatórios médico-legais serem "documentos incorporados no processo" (segundo a letra do próprio art. 88. \%/2/a do CPP), não poderão em principio ser divulgados pelos órgãos de Comunicação Social, excepto em muito estritas circunstâncias. A justificação deste regime particularmente severo reside no facto de o seu conteúdo abarcar aspectos

de justiça, ordenando, se for caso disso, a sua destruição ou que sejam entregues à pessoa a quem disserem respeito.

21 Art. 88.\%1 do CPP - É permitida aos órgãos de comunicação social, dentro dos limites da lei, a narração circunstanciada do teor de actos processuais que se não encontrem cobertos por segredo de justiça ou a cujo decurso for permitida a assistência do público em geral.

22 Art. 88.\%/2 do CPP - Não é, porém, autorizada, sob pena de desobediência simples:

a) A reprodução de peças processuais ou de documentos incorporados no processo, até

à sentença de $1 .^{\text {a }}$ instância, salvo se tiverem sido obtidos mediante certidão solicitada com menção do fim a que se destina, ou se para tal tiver havido autorização expressa da autoridade judiciária que presidir à fase do processo no momento da publicação;

23 Art. 90.\%2 CPP - A permissão de consulta de auto e de obtenção de cópia, extracto ou certidão realiza -se sem prejuízo da proibição, que no caso se verificar, de narração dos actos processuais ou de reprodução dos seus termos através dos meios de comunicação social. 
da intimidade das pessoas. Logo, para além do resguardo que lhes é devido como documentos de um processo penal, gozam ainda da tutela dispensada aos dados pessoais, protecção esta que é ainda mais severa atendendo a que são dados sensíveis.

\subsection{Institutos de medicina legal e comunicação social}

Os relatórios médico-legais, tal como já ficou referido, encontram-se a coberto do segredo de justiça.

Não deixa de ser curioso que o direito processual penal se tenha revestido de inúmeras cautelas no que respeita ao acesso e difusão de escutas telefónicas por parte dos jornalistas (arts. 187. $/ 1900^{\circ}$ do CPP) e, ao invés, adopte uma posição de certo modo mais "relaxada" em relação a outros elementos do processo que porventura revestem um carácter ainda mais privado, como sejam os extractos bancários e as perícias médico-legais, em relação aos quais não existe qualquer preceito expresso, de modo que valem para os mesmos as regras gerais que disciplinam a relação entre os media e o processo penal.

Ainda assim, se um dos funcionários do Instituto de Medicina Legal der ilegitimamente conhecimento do conteúdo de um acto processual penal ainda a coberto do segredo de justiça preencherá o tipo legal do art. $3710^{\circ}$ do CP. Também este preceito foi alterado por força da revisão de 2007, estipulando agora que comete o crime em causa todo aquele que ilegitimamente dê conhecimento, no todo ou em parte, de um processo penal em segredo de justiça, agora com o aditamento de " "independentemente de ter tomado contacto com o processo", o que tem sido considerado como uma forma de incluir de forma mais impressiva os jornalistas no círculo de pessoas vinculadas ao segredo ${ }^{24}$.

\section{0 conflito de interesses em presença}

Este é um palco de interesses em conflito. Por um lado, o direito à informação de que é titular o público em geral, e que caminha em paralelo com o direitos que os jornalistas têm de informar, a chamada liberdade de imprensa, que na verdade é uma forma qualificada da liberdade de expressão que a todos assiste. Por outro lado, o direito à privacidade das pessoas envolvidas, bem como o seu direito à honra e ao bom-nome. Este dualismo verifica-se em todas as situações nas quais a comunicação social pretende narrar algum acontecimento. Contudo, no âmbito do processo criminal entra em cena

24 Paulo Pinto de ALBUQUERQUE, Comentário..., p. 245. 
um outro interesse: o da investigação, em última instância subordinado à realização da justiça, que reclama a confidencialidade dos factos ocorridos e das diligências tomadas.

Sublinhe-se que os direitos e interesses que aqui se confrontam com a liberdade de expressão são exactamente aqueles que o art. 10.\%1 da Convenção Europeia dos Direitos do Homem (CEDH) elenca como motivos justificativos de ingerências estaduais naquela referida liberdade, e que como tal são aceites pela jurisprudência constante do Tribunal Europeu dos Direitos do Homem $(\mathrm{TEDH})^{25}$.

\subsection{Direito a informar e direito à informação}

Para além da sua consagração constitucional, este direito - na realidade, uma duplicidade de direitos - consta igualmente da Lei de Imprensa, a lei n. ${ }^{\circ}$ 2/99, de 13 de Janeiro, que imediatamente, no seu art. 1.\%/2, nos diz que a liberdade de imprensa abarca o direito de informar, de se informar e de ser informado, sem impedimentos nem discriminações.

\subsubsection{Direito a informar}

O direito de informar cabe aos meios de comunicação social e está constitucionalmente proclamado no art. $38 .^{\circ}$ da CRP, com a designação de liberdade de imprensa, sendo que esta, em boa verdade, abarca um amplo espectro de dimensões, entre as quais o direito de informar. A principal consequência deste último consiste no direito de aceder às fontes de informação ${ }^{26}$. Esta dimensão está expressamente consagrada no Estatuto do Jornalista (art. 8. ${ }^{\circ}$ da Lei n. ${ }^{0} 1 / 99$, de 13 de Janeiro ${ }^{27}$ ), embora esta norma esteja exclusivamente

25 “[L]a « nécessité » d'une quelconque restriction à l'exercice de la liberté d'expression doit se trouver établie de manière convaincante. Certes, il revient en premier lieu aux autorités nationales d'évaluer s'il existe un « besoin social impérieux » susceptible de justifier cette restriction, exercice pour lequel elles bénéficient d'une certaine marge d'appréciation. Lorsqu'il y va de la presse, comme en l'espèce, le pouvoir d'appréciation national se heurte à l'intérêt de la société démocratique à assurer et à maintenir la liberté de la presse. De même, il convient d'accorder un grand poids à cet intérêt lorsqu'il s'agit de déterminer, comme l'exige le paragraphe 2 de l'article 10, si la restriction était proportionnée au but légitime poursuivi" (caso Tourancheau et July c. France, processo n. ${ }^{\circ}$ 3886/00, 24 de Novembro de 1995, TEDH).

26 Art. 38.\%/2/b da CRP - A liberdade de imprensa implica:

$\mathrm{O}$ direito dos jornalistas, nos termos da lei, ao acesso às fontes de informação e à protecção da independência e do sigilo profissionais, bem como o direito de elegerem conselhos de redacção;

27 Art. 8.\% da Lei n. ${ }^{\circ} 1 / 99$ - $\mathrm{O}$ direito de acesso às fontes de informação é assegurado aos jornalistas: 
direccionada para os órgãos administrativos, sendo que, para estes efeitos, se considera sempre legítimo o interesse do jornalista no acesso às fontes de informação no contexto dos arts. $61 .^{\circ}$ a $63 .^{\circ}$ do Código de Procedimento Administrativo, isto é, o seu âmbito de aplicação restringe-se ao domínio administrativo (sensivelmente com o mesmo conteúdo veja-se o art. 22. ${ }^{\circ}$ da Lei de Imprensa).

Todavia, a restrição do âmbito de alcance desta norma do Estatuto do Jornalista está plasmada no seu art. 3. ${ }^{\circ}$, quando nos diz que este direito não inclui os processos em secreto de justiça, o que significa que esta matéria será disciplinada por um diferente normativo ${ }^{28}$, que não pode ser outro senão o disposto no próprio CPP.

\subsubsection{Direito a ser informado}

O direito a ser informado funda-se no pressuposto de que a informação na posse de entes públicos pertence, na realidade, ao público, isto é, à sociedade. $\mathrm{O}$ acesso à informação pretende traduzir a ideia de transparência do próprio Estado.

Uma vez que a comunidade não pode, ela própria e em todo o seu conjunto, estar presente na execução da justiça, é através da informação que recebe - nomeadamente pela comunicação social - que a sua presença se materializa, e que por conseguinte encontra dispositivos para formar a opinião pública indispensável à sindicância dos actos dos poderes públicos.

\subsection{Direito à privacidade}

$\mathrm{O}$ direito fundamental à privacidade encontra-se plasmado no art. 26.\%/1 da CRP, e é depois desenvolvido nos arts. 34. (direito à inviolabilidade do domicilio e da correspondência) e $35 .^{\circ}$ da mesma (proibição de tratamento

a) Pelos órgãos da Administração Pública enumerados no n. ${ }^{\circ} 2$ do artigo 2. ${ }^{\circ}$ do Código do Procedimento Administrativo;

b) Pelas empresas de capitais total ou maioritariamente públicos, pelas empresas controladas pelo Estado, pelas empresas concessionárias de serviço público ou do uso privativo ou exploração do domínio público e ainda por quaisquer entidades privadas que exerçam poderes públicos ou prossigam interesses públicos, quando o acesso pretendido respeite a actividades reguladas pelo direito administrativo.

28 Art. 8.\%3 da Lei n. $^{\circ} 1 / 99$ - $\mathrm{O}$ direito de acesso às fontes de informação não abrange os processos em segredo de justiça, os documentos classificados ou protegidos ao abrigo de legislação específica, os dados pessoais que não sejam públicos dos documentos nominativos relativos a terceiros, os documentos que revelem segredo comercial, industrial ou relativo à propriedade literária, artística ou científica, bem como os documentos que sirvam de suporte a actos preparatórios de decisões legislativas ou de instrumentos de natureza contratual. 
informático de dados referentes à vida privada). Para além disso, conhece refracções, quer no Código Civil (veja-se o direito de personalidade do art. $80 .^{\circ} \mathrm{CC}$ ), quer no CP (recordem-se os arts. $1900^{\circ}$ e seguintes, que tipificam as condutas de violação de domicílio, devassa da vida privada, devassa por meio de informática e violação de correspondência ou de telecomunicações).

No actual modelo processual pode verificar-se a publicidade do inquérito mesmo contra a vontade do arguido (suponha-se que o Ministério Público não requereu a sujeição do processo a segredo e que o juiz de instrução recusou o pedido do arguido nesse sentido), o que torna ainda mais premente a necessidade de assegurar mecanismos de protecção de informações da esfera da intimidade do arguido, que possam vir à baila durante o desenrolar do processo, nomeadamente durante a investigação.

A medicina legal é uma actividade técnica exercida por médicos, que se destina ao esclarecimento das autoridades judiciárias em matérias de carácter médico, para que depois as autoridades possam dar a essas informações técnicas a correspondente interpretação jurídica. Para desenvolver a sua função de esclarecimento é necessária a percepção directa dos factos por parte dos médicos, a qual ocorre mediante exames em pessoas vivas ou em cadáveres. Os problemas de privacidade que em ambas situações se suscitam são, compreensivelmente, distintos. É à autoridade judiciária que cumpre definir sobre que elementos recai o segredo de justiça (art. 86.\%/7 CPP), mais propriamente, avaliar se as perícias médico-legais, ou partes delas, devem estar incluídas nesse âmbito.

No que toca ao nosso particular tema podemos questionar em que medida é que a comunidade tem interesse em conhecer o referido conteúdo dos relatórios periciais. Tudo depende do exacto contexto. Por exemplo, é relevante saber características físicas do órgão sexual de um suposto agressor num crime sexual em que a vítima sustenta conseguir identificar tais características? Cremos que é. É relevante saber quais as marcas no corpo da suposta vítima, que indiciem as especificas humilhações sexuais de que foi objecto, relatadas com pormenores detalhados? Cremos que não é (excepto com consentimento da própria).

\subsubsection{Dados pessoais e dados sensíveis}

Tratando-se de pessoas vivas o exame consiste em, a partir do corpo ou seus componentes, recolher informações sobre o estado de saúde. O conteúdo de tais informações é, por conseguinte, classificado como dado de saúde, uma das modalidades mais sensíveis de dados pessoais.

Se partirmos do pressuposto de que a existência humana se divide em duas esferas - a pública e a privada - dados pessoais serão aqueles pertencentes à 
esfera privada, pelo que carecem de especial protecção. Aprofundando esta concepção à luz da teoria das esferas, deparamo-nos com uma zona tripartida, composta por três esferas concêntricas - a da vida íntima, a da vida privada e a da vida pública - sendo aquela primeira, que constitui o epicentro do nosso círculo, a mais restrita, e esta última a fronteira final dele e a mais ampla ${ }^{29}$.

De acordo com a lei de protecção de dados pessoais, a lei n. ${ }^{\circ} 67 / 98$, de 26 de Outubro (que transpõe para a ordem jurídica portuguesa a Directiva n. ${ }^{\circ}$ 95/46/CE, do Parlamento Europeu e do Conselho, de 24 de Outubro de 1995, relativa à protecção de dados de pessoas singulares no que respeita ao tratamento de dados e sua circulação), entende-se por dados pessoais "qualquer informação, de qualquer natureza e independentemente do respectivo suporte, incluindo som e imagem, relativa a uma pessoa singular identificada ou identificável («titular dos dados»); é considerada identificável a pessoa que possa ser identificada directa ou indirectamente, designadamente por referência a um número de identificação ou a um ou mais elementos específicos da sua identidade física, fisiológica, psíquica, económica, cultural ou social" (art. 3.\% /a da Lei n. ${ }^{\circ}$ 67/98).

$\mathrm{O}$ cidadão possui um direito fundamental à protecção dos seus dados (art. $35 .^{\circ}$ da $\mathrm{CRP}^{30}$ ), precisamente porque relevam da esfera da vida privada, tutelada em termos genéricos no art. $26 .^{\circ}$ da $\mathrm{CRP}^{31}$. Este direito contém, em boa verdade, dois direitos menores: o direito de impedir o acesso de estranhos a informações sobre a nossa vidas privada e familiar, por um lado; e o direito a que não sejam divulgadas informações sobre as referidas dimensões da nossa existência ${ }^{32}$.

29 Cfr. Pilar NICOLÁS JIMÉNEZ, La Protección Jurídica de los Datos Genéticos de Carácter Personal, Cátedra de Derecho y Genoma Humano - Editorial Comares, Bilbao - Granada, 2006, p. 111.

30 Art. 35.\%1 da CRP - Todos os cidadãos têm o direito de acesso aos dados informatizados que lhes digam respeito, podendo exigir a sua rectificação e actualização, e o direito de conhecer a finalidade a que se destinam, nos termos da lei.

Sobre a protecção de dados pessoais informatizados, José de Faria COSTA, "O Direito Penal, a Informática e a Reserva da Vida Privada”, in Comunicação e Defesa do Consumidor (AA. VV), Instituto Jurídico da Comunicação da Faculdade de Direito da Universidade de Coimbra, Coimbra, 1996, p. 69; Helena MONIZ, "Notas sobre a Proteç̧ão de Dados Pessoais perante a Informática”, Revista Portuguesa de Ciência Criminal, ano 7, fasc. 2 , Abril- Junho/1997, p. 246.

31 Art. 26.\% da CRP - A todos são reconhecidos os direitos à identidade pessoal, ao desenvolvimento da personalidade, à capacidade civil, à cidadania, ao bom nome e reputação, à imagem, à palavra, à reserva da intimidade da vida privada e familiar e à protecção legal contra quaisquer formas de discriminação.

32 J. J. Gomes CANOTILHO, Vital MOREIRA, Constituição da República Portuguesa Anotada, $4^{\text {a }}$ edição revista, Coimbra Editora, Coimbra, 2007, p. 467. 
Mais do que dados pessoais trata-se aqui de dados sensíveis. Estes são, de acordo com o art. 7.\% da Lei n..$^{\circ}$ 67/98, os dados relativos a conviç̧ões filosóficas ou políticas, filiação partidária ou sindical, fé religiosa, vida privada, origem racial e ética, saúde e vida sexual, bem como os de carácter genético ${ }^{33}$. Dada a especial conexão que apresentam com a área mais reservada da nossa vida a lei dispensa-lhes uma protecção acrescida.

\subsubsection{Regimes especiais de protecção}

Por conseguinte, mesmo que o processo não se encontre em segredo de justiça, os dados contidos nos relatórios periciais médico-legais beneficiam da protecção concedida aos restantes dados sensíveis, o que faz com que a publicidade que eventualmente (e hoje em regra) caracterize o processo penal não possa derrubar o especial regime de protecção de que estes dados auferem.

Esta mesma ideia foi sublinhada num despacho do Exm. ${ }^{\circ}$ Senhor Procurador-Geral Distrital do Porto, relativo à interpretação de algumas normas atinentes ao processo criminal: "os elementos processuais sujeitos a regime de segredo ou de sigilo de outra espécie derrogados para efeitos de produção de prova em processo criminal, devem permanecer sujeitos aos respectivos regimes normativos, considerando-se igualmente excepcionados da regra da publicidade" (o próprio n. $.^{\circ} 7 .^{\circ}$ do art. 86. ${ }^{\circ}$ do CPP acentua esta vertente, ainda que de forma mais limitada, ao ressalvar, como limite à publicidade do processo, os dados relativos à vida privada, mas apenas o que não constituam meio de prova, o que fica aquém do conteúdo do referido parecer). Semelhante tese foi afirmada no parecer da PGR n. ${ }^{\circ}$ P000252009, de 8 de Outubro de 2009: "Mas pelo facto de serem integrados no processo os elementos inerentes à privacidade das pessoas visadas não ficam desde logo privados da protecção que lhes é inerente que subsiste em tudo aquilo que não seja estritamente necessário à realização das finalidades do processo (...) Do mesmo modo, o acesso ao processo previsto no artigo $900^{\circ}$ do Código de Processo Penal deverá respeitar a especificidade dos elementos existentes no mesmo que possam ainda estar a coberto de um específico regime de segredo e da privacidade das pessoas visadas com o processo". Este raciocínio aplica-se integralmente aos relatórios de perícias médico-legais.

Por conseguinte, perfilhamos a conclusão adoptada no Parecer, segundo a qual o art. $90 .^{\circ}$ do CPP não permite o acesso a documentos que estejam a coberto de outros regimes de segredo.

33 Art. $7 . \% 1$ da Lei n. ${ }^{\circ} 67 / 98$ - É proibido o tratamento de dados pessoais referentes a convicções filosóficas ou políticas, filiação partidária ou sindical, fé religiosa, vida privada e origem racial ou étnica, bem como o tratamento de dados relativos à saúde e à vida sexual, incluindo os dados genéticos. 


\subsubsection{Dever de sigilo}

A existência de um regime legal de proteç̧ão pressupõe, do lado dos titulares do conhecimento dos dados em causa, um dever de sigilo, materializado na proibição de divulgação desses dados. A este dever se referem os arts. $75 .^{\circ}, 76 .^{\circ}$ e 78. ${ }^{\circ}$ do CC (cartas confidenciais) e o art. 195. ${ }^{\circ}$ do CP (violação do segredo).

No caso, está em jogo uma particular forma do dever de sigilo: o segredo médico, uma das modalidades de segredo profissional.

No seu parecer n. ${ }^{\circ}$ 16/94, de 2 de Maio de 1996, a PGR definiu o segredo profissional como "a reserva que todo o indivíduo deve guardar dos factos conhecidos no desempenho das suas funções ou como consequência do seu exercício, que lhe incumbe ocultar, seja porque lhe é pedido segredo ou porque este é inerente à natureza do respectivo serviço ou profissão". A preservação de tais informações consubstancia uma regra deontológica, cuja infracção poderá dar origem a um processo disciplinar. Estamos igualmente em presença de um bem jurídico-criminal, amparado por uma tipificação penal, pelo que a sua violação fará o agente incorrer na respectiva pena.

Tal como foi reconhecido pelo Conselho da Europa na Recomendação 1012, de 1985, o segredo profissional não só visa a tutela do interesse público atinente ao exercício de certas profissões, mas também a protecção do direito à privacidade das pessoas que com elas contactam e se vêm forçadas a revelar aos seus membros aspectos da vida íntima.

No caso em análise, juntamente com o segredo de justiça ("aquele especial dever, de que são investidas determinadas pessoas que intervêm no processo penal, de não revelar factos ou conhecimentos que só em razão dessa qualidade adquiriram", como resulta do Parecer 121/80, de 23 de Julho de 1981, da PGR) conflui, pois, o segredo médico.

\subsubsection{A privacidade aplicada aos mortos}

Parte substancial da actividade médico-legal incide sobre cadáveres. As autópsias consistem em exames efectuados nos órgãos internos do corpo do cadáver com o objectivo de determinar as causas da morte ou de estudar as suas alterações patológicas.

A decisão acerca da proibição ou admissibilidade do conhecimento dos dados recolhidos das autópsias está condicionada por aquilo que se decida relativamente ao estatuto do cadáver.

O Código Civil português, como de resto a maioria dos ordenamentos civis, refere que a personalidade jurídica cessa com a morte (art. $68 .^{\circ}$ do CC), ou seja, a pessoa que existia deixa de existir e, como tal, não se pode falar mais de direitos dada a ausência de uma entidade que os possa titular. Com 
a morte desaparece a pessoa, a sua esfera jurídica e os seus direitos, pois não existe a figura jurídica dos direitos post-mortem.

Mas a circunstância de não ter direitos não significa que o cadáver seja, sem mais, um objecto desprovido de qualquer tutela jurídica, se bem que alguma doutrina assim o qualifica. Mas não nos parece que se possa esquecer o resíduo personalista da pessoa que uma vez existiu. Uma célebre decisão de um tribunal de $1{ }^{a}$ instância de Lisboa (de 31 de Agosto de 1874) declarou que "os restos mortais de um individuo juridicamente não podem ser tidos como coisas para as tornar susceptíveis de apropriação e propriedade (...) mas sim como pessoas sem vida". Não iremos tão longe quanto esta decisão, ao ponto de concluir pela existência de uma pessoa sem vida, uma vez que tal figura não existe juridicamente. Pessoa é, para o direito, o ente que nasceu (o que exclui embriões e fetos) e que ainda não morreu (o que exclui cadáveres), segundo o disposto nos arts. $66 . \% 1$ e $68 . \% 1$ do $\mathrm{CC}^{34}$. É certo que o art. 71 . $^{\circ}$ do $\mathrm{CC}^{35}$ estabelece que os direitos de personalidade continuam a gozam de protecção depois da morte do seu titular mas, de acordo com a leitura da norma que me parece mais verosímil, tal não implica que o defunto seja, em si mesmo, titular de direitos. Parte da doutrina defende que esta norma deve ser lida como uma excepção à regra geral da extinção da personalidade ${ }^{36}$, isto é, como um prolongamento da existência de alguns dos direitos de que a pessoa foi titular. Todavia, quanto a nós, o conceito de personalidade postmortem deve ser recusado e, concomitantemente, também a titularidade de direitos nas mesmas circunstâncias. $\mathrm{O}$ que se mantém é o respeito devido à pessoa que existiu, e que podemos considerar um efeito póstumo da dignidade humana que um dia lhe assistiu. Logo, o que está aqui em causa não é o direito fundamental à dignidade humana, mas sim a dignidade da vida humana como valor objectivo, a qual continua a amparar o corpo humano

34 Art. $66 . \%$ do CC - A personalidade adquire-se no momento do nascimento completo e com vida.

Art. $68 . \% 1$ do CC - A personalidade cessa com a morte.

35 ARTIGO $71 .^{\circ}$ (Ofensa a pessoas já falecidas)

1. Os direitos de personalidade gozam igualmente de protecção depois da morte do respectivo titular.

2. Tem legitimidade, neste caso, para requerer as providências previstas no $n^{\circ} 2$ do artigo anterior o cônjuge sobrevivo ou qualquer descendente, ascendente, irmão, sobrinho ou herdeiro do falecido.

3. Se a ilicitude da ofensa resultar da falta de consentimento, só as pessoas que o deveriam prestar têm legitimidade, conjunta ou separadamente, para requerer as providências a que o número anterior se refere.

36 Diogo Leite de CAMPOS, Lições de Direitos da Personalidade, 2a ed., Coimbra Editora, Coimbra, 1992, p. 45; Rabindranath Capelo de SOUSA, O Direito Geral de Personalidade, Coimbra Editora, Coimbra, 1995, p. 192 
depois da morte da pessoa ${ }^{37}$. É nesta perspectiva que deve ser compreendida a tutela conferida ao nome e pseudónimo da pessoa falecida (arts. $73 .^{\circ}$ e $74 .^{\circ}$ do $\mathrm{CC}$ ), à sua honra, ao seu bom-nome e à intimidade da vida privada (arts. $76 .^{\circ} / 2$ e $77 .^{\circ}$ do CC) e à ofensa de pessoa falecida (art. $185 .^{\circ}$ do CP).

A posição do Tribunal Constitucional português é, sensivelmente, a mesma. Considerou que a concepção de Estado de Direito, e da dignidade humana que lhe é inerente, reclamam para o cadáver uma protecção equivalente à protecção da pessoa (viva) que o precedeu, se bem que recuse ao cadáver o estatuto de pessoa e, por conseguinte, a titularidade de direitos (decisão do Tribunal Constitucional n. ${ }^{\circ}$ 130/88, de 8 de Junho de 1988).

Por conseguinte, os elementos relativos ao defunto contidos no relatório da autópsia devem igualmente ser objecto de protecção ${ }^{38}$. Esta ideia de recato da vida privada do falecido fundamentou a opção legislativa de omitir a causa da morte nos assentos de óbito do registo civil (até ao Decreto-Lei n. ${ }^{\circ}$ 54/90, de 13 de Fevereiro, esta menção era obrigatória, mas hoje em dia o art. 201. ${ }^{\circ}$ do CC não a refere já).

\subsection{A realização da justiça}

A realização da justiça, resultante do bom andamento do processo, é outro dos valores que se pretende salvaguardar com o segredo de justiça,

37 Jorge MIRANDA, Rui MEDEIROS (Constituição Portuguesa Anotada, Tomo I, Coimbra Editora, Coimbra, 2005, p. 284) escrevem que no seio de uma ordem juridica fundada no principio da digidade humana merecem tutela o bom nome, a reputação e a intimidade da pessoa falecida, mas não esclarecem se se referem a uma tutela subjectiva ou meramente objectiva. Defendendo igualmente a ideia de uma dignidade humana que sobrevive à morte física, Paula Ribeiro de FARIA, Aspectos Jurídico-Penais dos Transplantes, Universidade Católica Portuguesa, Porto, 1995, p. 124; João Carlos Simões Gonçalves LOUREIRO, Transplantações: Um Olhar Constitucional, Colecção Argumentum/9, Coimbra Editora, Coimbra, 1995, p. 23.

38 No mesmo sentido veja-se o parecer da PGR n. ${ }^{\circ}$ P000302005.

Esta opinião foi igualmente defendida no parecer n. ${ }^{\circ}$ 29/98, de 24 de Setembro de 1998: “A causa da morte é considerada como um dado sensível, ou seja, como um daqueles dados a que o cidadão tem direito à salvaguarda contra a devassa ou difusão, e em relação aos quais é proibido o acesso de terceiros. (...)

Fácil é intuir que a causa da morte pode revelar-se degradante para a imagem do falecido e ou da sua família. (...) E, sempre que possível, deve evitar-se personalizar a informação, minimizando os riscos de potenciais ofensas à intimidade da vida privada ou familiar".

Em contrapartida, anteriormente, no parecer n. ${ }^{\circ} 129 / 83$, de 3 de Junho de 1983, entendeu-se que "[c]om a morte cessa a vida privada e familiar do defunto, não fazendo sentido que, após aquela, se admitam violações originárias à intimidade desta”. Além do mais, uma vez que o caso envolvia figuras públicas, mesmo que se tivesse verificado uma violação da intimidade, esta seria lícita, pois o protagonismo dos envolvidos justificava, segundo se defendeu, a prevalência do direitos dos cidadãos a ser informado. 
pois este não pode ser visto unicamente como parte do conteúdo de um direito individual dos participantes processuais. A divulgação de detalhes do processo põe em risco a liberdade dos juízes face às pressões da opinião comunitária, a incolumidade das provas e toda a investigação em si mesma. Em suma, pretende também salvaguardar a acção penal e o interesse na boa administração da justiça, na medida em que o segredo "é relevante também para o Ministério Público e para a máquina judicial" 39

No acórdão 428/2008, de 12 de Agosto de 2008, o Tribunal Constitucional declarou inconstitucional o art. 89.\%/3 emergente da Lei n. ${ }^{\circ}$ 48/2007, por violação do artigo $20 . \% 3$ da CRP, quando interpretado como autorização inderrogável ao arguido para, no âmbito de um processo em segredo de justiça e antes de finalizado o inquérito, consultar irrestritamente "todos os elementos do processo, neles incluindo dados relativos à reserva da vida privada de outras pessoas, abrangendo elementos bancários e fiscais sujeitos a segredo profissional, sem que tenha sido concluída a sua análise em termos de poder ser apreciado o seu relevo e utilização como prova, ou, pelo contrário, a sua destruição ou devolução, nos termos do $n .^{\circ} 7$ do artigo $86 .^{\circ}$ do Código de Processo Penal".

Ora, se isto é assim quando a quebra do segredo se justifica pelo beneficio que o arguido retiraria da consulta do processo em termos de preparação da sua defesa, por maioria de razão o deve ser quando o segredo de justiça seja confrontado com o desempenho da actividade jornalística. Não querendo aqui proceder a uma hierarquização de direitos - aliás, impossível de ser feita - parece-nos que merece maior tutela o direito de defesa do arguido em processo penal do que o direito de informar e de ser informado sobre questões que estão mais próximas da indiscrição do que da informação legítima. De facto, grande parte do conteúdo dos referidos relatórios diz respeito a pormenores íntimos da vida das pessoas, que poderão ser relevantes para efeitos de aplicação da justiça, mas não para o cidadão em geral, que em regra apenas os quererá conhecer por força da inata curiosidade humana.

\section{As tentativas de harmonização dos interesses em conflito}

Se é verdade que estamos em presença de interesses preponderantes que podem ditar o levantamento da publicidade do processo, também é verdade que outros interesses igualmente relevantes - e, por vezes, os mesmos interesses - têm capacidade para abrir algumas brechas no secreto de justiça

39 Intervenção do deputado José Magalhães, DAR, II Série-RC, n. ${ }^{\circ}$ 75, de 16 de Abril de 1997, p. 2176 
que tenha sido anteriormente estabelecido. De modo que, mesmo que nos encontremos numa fase secreta do processo, não está totalmente excluído que os relatórios médico-legais possam ser divulgados pela comunicação social. Contudo, na condição de ser omitida quer a identidade da pessoa a quem dizem respeito, quer os dados mais íntimos dos ditos relatórios. Em suma, não se exclui que os jornalistas possam divulgar uma parte do conteúdo dos relatórios das perícias médico-legais, precisamente aquela que não contende com dados sensíveis. Poderá, por exemplo, relatar o facto a que o crime diz respeito, se este já for do conhecimento público, mas não outras informações, tais como o modo como o crime se perpetrou no corpo da vítima, sinais e particularidades físicas das pessoas, nem a identificação pessoal.

Não obstante, e mesmo no que respeita a dados sensíveis, cremos que não pode estar totalmente excluído o seu acesso por parte dos jornalistas. Efectivamente, a circunstância de os dados pessoais incluídos nos relatórios médico-legais constituírem dados particularmente sensíveis não implica que se lhes proíba inteiramente o acesso. Não existem direitos fundamentais absolutos, nem mesmo o direito à protecção da esfera mais recôndita da intimidade ${ }^{40}$. Consequentemente, em alguns casos (necessariamente delimitados e excepcionais) deve admitir-se o acesso a dados sensíveis incorporados em relatórios médico-legais ${ }^{41}$, atendendo aos critérios de proporcionalidade plasmados no art. $18 .^{\circ}$ da $\mathrm{CRP}^{42}$. Esta derrogação à proibição genérica de acesso ocorrerá quando o direito à informação se sobreponha à imperiosa necessidade de privacidade. Certamente que este direito à informação deve ser especialmente qualificado, e não uma mera pretensão em ser informado. Ou seja, um direito à informação que se prenda com o interesse público na administração da justiça ${ }^{43}$.

A concreta delimitação da matéria que pode ser conhecida e divulgada pela Comunicação Social (e note-se que não existe necessária coincidência entre uma e outra) cabe às autoridades judiciais - juiz de instrução e de julgamento - tradicionais garantes dos direitos de defesa das pessoas envolvidas.

40 Jorge MIRANDA, Rui MEDEIROS, Constituição..., cit., p. 386

41 "Com efeito, assim como são admissíveis certas derrogações ao princípio do segredo de justiça, precisamente impostas pelo interesse público da descoberta dos crimes e da averiguação da responsabilidade dos seus agentes, é lícito admitir que o interesse da protecção da intimidade da vida privada possa ser sacrificado em favor desse mesmo interesse público, quando esse sacrifício não possa, de todo ser, ser evitado" (Parecer n. ${ }^{\circ}$ 121/80 da PGR).

42 Art. 18.\%/2 CRP - A lei só pode restringir os direitos, liberdades e garantias nos casos expressamente previstos na Constituição, devendo as restrições limitar-se ao necessário para salvaguardar outros direitos ou interesses constitucionalmente protegidos.

43 Vide o parecer n. ${ }^{\circ} 121 / 80$ da PGR. 
Esta tentativa de harmonização de interesses está igualmente presente no art. $192 .^{\circ}$ do $\mathrm{CP}^{44}$, que descarta da punição por crime de intromissão na vida privada a divulgação de factos da vida privada ou relativos a doenças graves (não se alcança o sentido desta dicotomia, pois as questões de saúde cabem sempre e necessariamente na vida privada), na medida em que configurem um meio adequado para a realização de um interesse público relevante, interesse este que se pode eventualmente prender com o direito a ser informado, mas somente quando se trate de um interesse qualificado e não de mera curiosidade.

O próprio CPP tem consciência da necessidade de prever algumas derrogações. Ainda que não expressamente conexas com matérias relativas a dados sensíveis pretendem demonstrar que o resguardo de certas informações, por mais relevante que seja o fundamento em que se encore, não pode ser levado ao extremos de as "apagar" por completo. Em conformidade, o n. ${ }^{\circ} 9$ do art. 86. ${ }^{\circ}$ do CPP estipula que a autoridade judiciária pode permitir que determinadas pessoas tenham conhecimento de um acto ou documento, desde que necessário para restabelecer a verdade ou para o exercício de um direito por parte dos interessados ${ }^{45}$. No n. ${ }^{\circ} 11 .^{\circ}$, por sua vez, permite que a autoridade judiciária autorize que seja dado conhecimento de um acto ou documento que se encontre em segredo de justiça se necessário a um processo criminal, disciplinar ou civil ${ }^{46}$. Qualquer destas duas possibilidades são poderes-deveres por parte das autoridades judiciárias. Estas não estão vinculadas a fazê-lo, já que tal opção depende inteiramente do seu juízo. Diferente é a redacção do n. ${ }^{\circ}$ 12 do art. $86 .^{\circ}$ do CPP, segundo o qual, quando o processo se relacione com um acidente rodoviário, a autoridade judiciária autoriza a passagem de um certificado mediante o qual se dá conhecimento de um acto ou documento em

44 Art. $192{ }^{\circ} \mathrm{CP}-$ Devassa da vida privada

1. Quem, sem consentimento e com intenção de devassar a vida privada das pessoas, designadamente a intimidade da vida familiar ou sexual:

d) Divulgar factos relativos à vida privada ou a doença grave de outra pessoa;

é punido com pena de prisão até um ano ou com pena de multa até 240 dias.

2. O facto previsto na alínea $d$ ) do número anterior não é punível quando for praticado como meio adequado para realizar um interesse público legítimo e relevante.

45 Art. 86.\% 9 CPP - A autoridade judiciária pode, fundamentadamente, dar ou ordenar ou permitir que seja dado conhecimento a determinadas pessoas do conteúdo de acto ou de documento em segredo de justiça, se tal não puser em causa a investigação e se afigurar:

a) Conveniente ao esclarecimento da verdade; ou

b) Indispensável ao exercício de direitos pelos interessados.

46 Art. 86.\%11 CPP - A autoridade judiciária pode autorizar a passagem de certidão em que seja dado conhecimento do conteúdo de acto ou de documento em segredo de justiça, desde que necessária a processo de natureza criminal ou à instrução de processo disciplinar de natureza pública, bem como à dedução do pedido de indemnização civil. 
segredo de justiça para efeitos de cumprimento de finalidades relacionadas com o processo criminal, disciplinar ou civil ${ }^{47}$. Uma vez que a norma utiliza aqui a expressão "autoriza" - e não a já nossa conhecida "pode autorizar" - pareceria que anula a possibilidade de avaliação pessoal e que este acto surge, ao invés, como uma obrigação. Contudo, a remissão para o número anterior esclarece que ambos os preceitos se mantêm ainda na liberdade de avaliação da autoridade judiciária ${ }^{48}$.

$\mathrm{O}$ art. $18 .^{\circ}$ da CRP é invocado sempre que se verifique um conflito de direitos fundamentais, na medida em que estabelece regras que há que respeitar quando seja necessário limitar estes direitos ${ }^{49}$. Pois bem, a resolução de um conflito passa necessariamente por restrições sucessivas a cada um dos direitos, até encontrar um ponto óptimo de equilíbrio que permita a máxima satisfação de todos eles com o mínimo de limitações ao seu conteúdo. Somente quando tal equilíbrio não seja possível se deve partir para a anulação de um dos direitos, o mais débil no caso concreto, a favor do direito mais forte ${ }^{50}$.

No nosso particular dilema, cabe à autoridade judiciária confrontar o direito à reserva da vida privada dos sujeitos das perícias médico-legais com o hipotético interesse legítimo daquele que solicita o acesso aos relatórios. Note-se que a elevação do "interesse legítimo" a critério de avaliação do comportamento apresenta uma relação bastante próxima com a actividade dos jornalistas, pois já no art. $180 .^{\circ}$ do $\mathrm{CP}$, a propósito dos crimes contra a honra, exclui-se a criminalização daqueles que actuem em prossecução de um interesse legítimo. Agora a questão centra-se em saber se os jornalistas,

47 Art. 86.\%12 CPP - Se o processo respeitar a acidente causado por veículo de circulação terrestre, a autoridade judiciária autoriza a passagem de certidão:

a) Em que seja dado conhecimento de acto ou documento em segredo de justiça, para os fins previstos na última parte do número anterior e perante requerimento fundamentado no disposto na alínea $a$ ) do n. ${ }^{\circ} 1$ do artigo $72 .{ }^{\circ}$

48 Analisando a redacção destas normas, e chegando a esta mesma conclusão, o parecer da PGR n. ${ }^{\circ}$ P000302005.

49 Sobre esta norma, J. J. Gomes CANOTILHO, Vital MOREIRA, Constituição da República Portuguesa Anotada, 4 a edição revista, Coimbra Editora, Coimbra, 2007, p. 381 ss.

Sobre os limites aos direitos fundamentais, Luis AGUIAR DE LUQUE, "Los Limites de los Derechos Fundamentales", Revista del Centro de Estudios Constitucionales, 14, 199, p. 13/34 ; Martin BOROWSKI, "La Restricción de los Derechos Fundamentales", Revista Española de Derecho Constitucional, 59, año 20, 2000, p. 39 ss.; José Manuel Cardoso COSTA, "Les Conditions de la Limitation des Droits Fondamentaux dans le Droit et la Justice Constitutionnelle Portugaise", in Constitution - Lex Superior (AA.VV), Belgrade, 2004, p. 73 ss. ; Gregorio PECES-BARBA MARTÍNEZ, Curso de Derechos Fundamentales, Teoría General, Universidad Carlos III de Madrid, Boletín Oficial del Estado, Madrid, 1999, p. 590/616.

50 José Carlos Vieira de ANDRADE, Os Direitos Fundamentais na Constituição Portuguesa de 1976, 2. a Almedina, Coimbra, 2001, p. 310 ss.; J. J. Gomes CANOTILHO, Constituição Dirigente e Vinculação do Legislador (reimpressão), Coimbra Editora, Coimbra, 1994, p. 199, 200. 
no exercício das suas funções profissionais, são sempre e necessariamente titulares de um interesse legítimo, fundado no seu direito a informar e, concomitantemente, no direito do público a ser informado. Será que a sua relevantíssima função social confere ao jornalista um interesse legítimo que se pode dizer ínsito à sua profissão? Mesmo que assim se entenda, tal não implica que esse interesse tenha sempre que prevalecer sobre o direito à intimidade dos envolvidos. Mas parece-nos que nem sequer é verdadeira esta correlação necessária entre o direito a informar e a titularidade de um interesse legítimo ${ }^{51}$. Por exemplo, quando o jornalista procure pormenores macabros sobre a intimidade mais reservada da pessoa - com vista, não a informar o público, mas sim a satisfazer a curiosidade mórbida dos leitores para fomentar o aumento das vendas - não se vislumbra qualquer interesse que mereça protecção legal.

Esta ideia de ponderação e harmonização resulta também do Estatuto do Jornalista (Lei n. ${ }^{\circ}$ 1/99) que, no seu art. 14. ${ }^{\circ}$, impõe ao jornalista o dever de não identificar certas pessoas (as vítimas de crimes contra a liberdade e a auto-determinação sexual, bem como os menores que tenham sido objecto de medidas sancionatórias) e, concomitantemente, o dever de salvaguardar a privacidade das pessoas ${ }^{52}$. Uma das principais dificuldades nesta matéria resulta da indeterminação do conceito de privacidade, dado que os seus contornos oscilam continuamente com a evolução da sociedade, conduzindo a uma permanente comunicabilidade entre o sector público e o privado ${ }^{53}$.

Há que reconhecer os inúmeros perigos de uma descrição incorrecta dos factos nos media, já que se corre o risco da actividade de investigação lesar a presunção da inocência da pessoa que está a ser investigada e, assim, perturbar a decisão final. Além do mais, provoca uma desnecessária consternação social.

No caso concreto que nos preocupa a tudo isto acrescente a particular sensibilidade de algumas das informações em jogo, relativas ao corpo, à

51 José de Faria COSTA, Estudos Comemorativos do $1500^{\circ}$ Aniversário do Tribunal da Boa-Hora, 1995, p. 196, apud Comentário Conimbricense do Código Penal, Parte Especial, Tomo I, (dirigido por Jorge de Figueiredo Dias), Coimbra Editora, Coimbra, 1999, p. 616.

52 Art. $14 .^{\circ}$ da Lei n. ${ }^{\circ} 1 / 99$ - Independentemente do disposto no respectivo código deontológico, constituem deveres fundamentais dos jornalistas:

c) Abster-se de formular acusações sem provas e respeitar a presunção de inocência;

d) Não identificar, directa ou indirectamente, as vítimas de crimes contra a liberdade e autodeterminação sexual, bem como os menores que tiverem sido objecto de medidas tutelares sancionatórias;

f) Abster-se de recolher declarações ou imagens que atinjam a dignidade das pessoas;

g) Respeitar a privacidade de acordo com a natureza do caso e a condição das pessoas;

53 Manuel da Costa ANDRADE, Comentário Conimbricense..., cit., p. 730. 
saúde, ao mapa genético, em suma, ao núcleo mais recôndito da nossa vivência pessoal.

Em conformidade, a revelação de qualquer informação deve pautar-se por critérios de máxima prudência e objectividade. Não é tarefa fácil realizar este equilíbrio, desde logo porque a justiça e a comunicação social se pautam por tempos distintos: enquanto a primeira se caracteriza por um tempo lento e ritualizado, já a segunda move-se de forma dinâmica, muitas vezes mais rapidamente do que a sociedade pode aceitar e, por maioria de razão, do que a justiça consegue acompanhar ${ }^{54}$.

Resumo: Quem tem medo dos jornalistas? Media, segredo de justiça e perícias médico-legais Hoje em dia os media expõem publicamente todas as dimensões da nossa vida, inclusive as respeitantes a uma investigação criminal e correspondente punição. Por um lado, a liberdade de imprensa é um direito fundamental (uma dimensão da liberdade de expressão) que representa uma forma indispensável de informar a sociedade e de permitir o controlo do poder judicial. Por outro lado, a revelação de estes factos atenta contra a reserva da vida privada e contra a eficácia na administração da justiça, sobretudo quando o processo se encontre em segredo de justiça.

Quando as informações divulgadas se referem a relatórios médico-legais o problema é particularmente complexo uma vez que estamos em presença de informações de natureza mais íntima. A lei portuguesa sobre protecção de dados pessoais qualifica como dados sensíveis os que respeitem à saúde, à vida sexual e ao património genético da pessoa, e atribui-lhes uma protecção especialmente gravosa. Deste modo, os relatórios médico-legais beneficiam, não somente da protecção do segredo de justiça, mas também da protecção dos dados sensíveis. Por conseguinte, o acesso dos jornalistas a estes relatórios deve ser severamente limitado.

Palavras-chave: Jornalistas; liberdade de imprensa; relatórios médico-legais; processo criminal; segredo de justiça; dados sensíveis; reserva da vida privada.

Summary: Who is afraid of journalists? Media, Camera Proceeding and forensic expertises Nowadays the media publicly expose all dimensions of our life, including the ones respecting to a criminal investigation and the application of the corresponding penalty. On the one hand, freedom of press is a fundamental right (a dimension of the right to freedom of expression) which represents an indispensable form of informing the society and to allow the control over the judicial power. On the other hand, the revelation of these facts attempts against the reserve of private life and against the efficiency in the administration of justice, mainly when the procedure is still camera proceeding.

54 Felisbela LOPES, Comunicação e Sociedade 2, Cadernos do Noroeste, Série Comunicação, Vol. 14 (1-2), 2000, p. 346. 
When the information released refers to a medico-legal report, the problem is particularly complex because we are in front of information with a more intimate nature. The Portuguese law on protection of personal data qualifies as sensitive data the ones regarding health, sex life and genetic patrimony of the person, and attributes them an especially strict protection. As a result, medico-legal reports enjoy, not only from the protection of camera proceeding, but also from the protection of sensitive data. Therefore, journalists' access to these reports must be severely limited.

Key-words: Journalists; freedom of press; medico-legal reports; criminal procedure; camera proceeding; sensitive data; reserve of private life.

Résumé: Qui a peur des journalistes? Media, secret de justice et expertises médico-légales Aujourd'hui les media exposent publiquement tous les dimensions de notre vie, inclusive ceux que respectent à une investigation criminelle et à l'application de la correspondante punition. D'un côté, la liberté de presse est un droit fondamental (une dimension de la liberté d'expression) qui représente une forme indispensable d'informer la société et de permettre le control du pouvoir judiciaire. D'un autre côté, la révélation de ces faits attente contra la réserve de la vie privée et contre la efficacité de la administration de la justice, surtout quand le procès est encore en secret de justice.

Lors que les informations divulguées se rapportent à un rapport médico-légal, le problème est particulièrement complexe parce qu'on est en présence de information de nature plus intime. A propos de la protection des données personnelles, la loi portugaise qualifie comme données sensibles ceux que respectent à la santé, à la vie sexuelle et au patrimoine génétique de la personne, et les attribue une protection spécialement graveuse. Ainsi, les rapports médico-légaux bénéficient, non seulement de la protection du secret de justice, mais aussi de la protection de données sensibles. Conséquemment, l'accès des journalistes à ces rapports doit être sévèrement limité.

Mots-clés: Journalistes; liberté de presse; rapports médico-légaux; procès criminel; secret de justice; données sensibles; réserve de la vie privée.

\section{Pedido de separatas:}

VERA LÚCIA RAPOSO

vera@fd.uc.pt 